\title{
Aproximación a la literacidad crítica
}

\author{
Daniel Cassany* \\ Josep M. Castellà $* *$
}

\section{Resumen}

Exploramos aquí los conceptos de literacidad y de critica, o de lectura y escritura de ideologías, tomando "ideología" como el posicionamiento que hace un autor en su texto sobre cualquier cuestión (política, social, deportiva, etc.). Analizamos el campo semántico de ambos conceptos, sus raíces filosóficas, pedagógicas y lingüísticas, y los vocablos usados en varios idiomas para denominarlos. Formulamos finalmente la distinción teórica entre un lector crítico y acrítico, a partir de las aportaciones del Análisis Crítico del Discurso, y lo ejemplificamos con el caso de un cartel político de 5 palabras.

Palabras clave: Alfabetización. Lectura.

* Daniel Cassany es Doctor en Didáctica de la Lengua por la Universitat de Barcelona (1995).

** Josep M. Castellà es Doctor en Lingüística por la Universitat Pompeu Fabra. Ambos son profesores titulares de la Universitat Pompeu Fabra y miembros del grupo de investigación Literacitat Crítica. 


\section{Presentación}

La orientación sociocultural de la lectura y la escritura (o literacidad, según el título) sugiere que leer y escribir no solo son procesos cognitivos o actos de (des)codificación, sino también tareas sociales, prácticas culturales enraizadas históricamente en una comunidad de hablantes. Además de usar signos y de poner en juego procesos cognitivos, al leer las personas hacemos cosas en sociedad, interactuamos con nuestra familia, colegas y conciudadanos, ejercemos nuestros derechos democráticos, nuestras obligaciones laborales, nuestra actividad diaria en un entorno letrado. En este artículo presentaremos esta orientación sociocultural de lo letrado, además de poner énfasis en la necesidad de adoptar una perspectiva crítica en la educación. ${ }^{1}$

A continuación, después de presentar el concepto y el término literacidad (apartado 2), exploramos brevemente y caracterizamos el concepto esencial de criticidad (apartado 3), para terminar resumiendo el punto de vista que adopta una perspectiva sociocultural sobre la lectura (apartado 4). Para caracterizar lo crítico, repasamos sucintamente las significaciones que ha adoptado en la historia reciente (3.1.), resumimos y comentamos las cuatro aproximaciones más importantes que ha tenido - en nuestra opinión - (3.2.), delimitamos la frontera entre la lectura crítica y la acrítica (3.3.) y ejemplificamos el concepto con un caso real (3.4.). Esperemos que esta breve introducción sirva para presentar a los investigadores brasileños esta nueva orientación del estudio de la lectura y la escritura.

\section{Concepto y término: literacidad}

El concepto literacidad (literacy en inglés) incluye un amplio abanico de conocimientos, prácticas sociales, valores y actitudes relacionados con el uso social de los textos escritos en cada comunidad. En concreto, la literacidad incluye el dominio y el uso del código alfabético, la construcción receptiva y productiva de textos, el conocimiento y el uso de las funciones y los propósitos de los diferentes géneros discursivos de cada ámbito social, los roles que adoptan el lector y el autor, los valores sociales asociados con estos roles (identidad, estatus, posición social), el conocimiento que se construye en estos textos y que circula en la comunidad, la representación del mundo que transmiten, etc. 
Así, la literacidad incluye tanto las investigaciones sobre ortografía o correspondencia sonido-grafía, como el análisis de géneros discursivos escritos, la investigación antropológica sobre el uso de la escritura en una comunidad, el estudio longitudinal o histórico del devenir de una práctica escrita en un ámbito social, las teorías cognitivas sobre los procesos mentales implicados en la lectura y la escritura o las reflexiones más políticas sobre los efectos sociales de la literacidad y el uso que determinados grupos hacen de la herramienta de la escritura para mantener el poder. En consecuencia, las investigaciones que se presentan en este simposio se enmarcan también en este campo.

Las dificultades para referirse en español a este concepto (al literacy inglés) son viejas y conocidas, y equiparables a las que padecen otros idiomas como el francés (littératie / alphabétisme / lettrisme ), el catalán (alfabetització, alfabetisme, literacitat), el portugués (letramento / alfabetiçao /literacia) o el alemán (alphabetiezierung / literacy). Encontramos términos como alfabetización (quizá el más corriente en España), alfabetismo (la opción más reciente que usan varias traducciones del inglés), escrituralidad (por oposición a oralidad), literacia o literacía (según los autores, calcando el término inglés), cultura letrada o cultura escrita (por oposición a una cultura analfabeta u oral). También se usan formas más corrientes del tipo lectura y escritura, como se puede ver en los títulos de las comunicaciones, las ponencias y las secciones de los principales congresos hispanos (de la sección latinoamericana de la International Reading Association, de la Cátedra UNESCO de Lectura y escritura de Buenos Aires, Cali y Valparaíso o de otras instituciones).

Pero ninguna de estas formas se ha impuesto entre los investigadores. Causa asombro asistir a encuentros internacionales y constatar cómo los diferentes asistentes alternan de modo caótico los términos anteriores. También puede llegar a irritar experimentar en el uso cotidiano las limitaciones que presenta cada opción. Veamos algunos ejemplos de las dificultades de algunos términos:

- Alfabetización parece referirse solo a la adquisición del alfabeto (pero no a la cultura letrada) y carga con las connotaciones peyorativas asociadas a persona o comunidad analfabeta (inculta, pobre, primitiva. Además, presenta evidentes dificultades en frases como alfabetizar en un alfabeto latino. 
- Alfabetismo tiene la ventaja de disponer del término corriente y conocido analfabetismo, pero carga con las mismas connotaciones que alfabetización y resulta nuevo y desconocido para muchos.

- Letrado (persona letrada, comunidad letrada) permite establecer una distinción sugerente y útil entre persona alfabetizada (conocedora del alfabeto o iniciada en su uso) y persona letrada (culta, que domina muy bien las prácticas lectoras y escritoras), pero carece de sustantivo (en español no existe equivalencia del portugués letramento o del francés lettrisme) lo cual lleva al investigador a tener que buscar circunloquios como "el estudio de las prácticas letradas" o "el dominio de lo letrado".

- Escrituralidad carece de adjetivo y tampoco está muy extendido en América - y mucho menos en España.

- Cultura escrita es muy abstracto y aunque resulte útil para referirse de manera global al ámbito de estudio, en otras ocasiones constituye una denominación poco operativa.

- Literacía y literacidad suelen verse como préstamos del inglés literacy y pueden generar rechazo, además de parecer algo raros o infrecuentes a muchos docentes e investigadores.

En los últimos años varios autores de ambos lados del Atlántico (AMES, 2002; ZAVALA, 2002; MARÍ, 2005; VICH; ZAVALA, 2004) han empezado a usar y promover el término literacidad, con la intención de unificar todas las denominaciones y contribuir a aclarar el campo, y nosotros nos sumamos a esta propuesta. Literacidad designa sin problemas todo el ámbito conceptual descrito y permite formar otros neologismos como multiliteracidad, biliteracidad o literacidad electrónica. Además, el español tiene vocablos corrientes con etimología cercana (literario, literato, literal). Quizás no soluciona todos los problemas: puede sonar algo raro al principio y carece de adjetivo. Pero se trata de una propuesta que va ganando terreno. Por otro lado, tampoco es descabellado que los términos más neutros y técnicos (oncología, dermatología) convivan con denominaciones más corrientes y connotadas (cáncer, enfermedades de la piel). 


\section{Concepto y término: criticidad}

Las dificultades para usar provechosamente el vocablo crítico (crítica, criticidad, acrítico) son solo conceptuales. Se trata de un término corriente en varias disciplinas desde hace algunas décadas: didáctica de la lengua (comprensión crítica, lectura crítica), educación (pensamiento crítico, pedagogía crítica), ciencias del lenguaje (Análisis Crítico del Discurso), como también en filosofía, estudios culturales, etc. En cada disciplina y en cada momento se ha usado con significados diferentes y eso dificulta su uso preciso actual.

Por ejemplo, es un término corriente en currículos, boletines (Reading on Line, Kairós) y webs. El onceavo estándar de lengua y literatura del NCTE (National Council of Teachers of English en EUA) y la Internacional Reading Association se refiere a la participación creativa, reflexiva y critica de los estudiantes en distintas comunidades alfabetizadas. ¿Pero qué significa exactamente crítica en estos contextos? Para responder a esta pregunta, sugerimos a continuación una brevísima síntesis histórica de autores y disciplinas que han usado el término, distinguimos cuatros grandes perspectivas, exploramos la distinción críticolacrítico y comentamos un ejemplo.

\section{Mapa de las raíces del concepto}

El mapa siguiente enumera las disciplinas, los grupos de autores y las ideas más relevantes - desde nuestro punto de vista, por supuesto - que se han manejado alrededor del concepto de criticidad. Aquí es imposible referirse con suficiente detalle y merecimiento a todos, por lo que aquí solo ofreceremos algunas pinceladas básicas y orientadoras.

Las revisiones históricas (SIEGEL; FERNÁNDEZ, 2000; LEAL CARRETERO, 2003; CASSANY, 2005) atribuyen a los filósofos de la Escuela de Frankfurt a partir de los ańos veinte del siglo pasado el moderno concepto de criticidad, que desarrolla una actitud de revisión, discusión y reformulación de las situaciones sociales, aceptadas comúnmente de manera demasiado irreflexiva. Así, Horkheimer critica las pretensiones de objetividad absoluta del positivismo científico y propone, para superar la dicotomía teoría-práctica, una conexión más estrecha entre las necesidades de las personas y los objetivos de la investigación. 


\section{Teoría crítica}

$\begin{array}{ll}\text { ACD } & \text { Escuela de Frankfurt: Horkheimer, } \\ \text { Adorno, Habermas, etc. "el esfuerzo }\end{array}$ intelectual por no aceptar sin reflexión y por simple hábito las ideas, los modos de actuar y las relaciones sociales dominantes." Max Horkheimer. van Dijk, Fairclough, Wodak. El habla expresa, reproduce y legitima las desigualdades sociales.

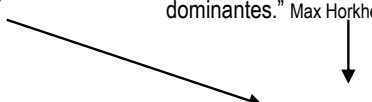

Nuevos estudios de literacidad
Literacidad

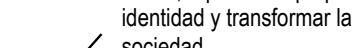

\section{Pedagogía crítica}

Freire, Macedo, Giroux. La literacidad es el medio para desarrollar la conciencia crítica, repensar la propia dentidad y transformar la sociedad.

\section{Estudios culturales y} políticos

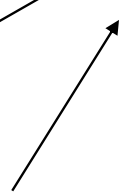

Derrida, Foucault.

El discurso construye la identidad, las relaciones sociales y la visión del mundo del lector. Los textos no pueden interpretarse de forma absoluta.
Postmodernismo: ruptura con los paradigmas "universales": feminismo, antiracismo, postcolonialismo, nacionalismo, ecología.

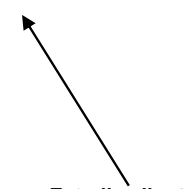

Estudios lingüísticos y literarios

Halliday: relación entre gramática y registro (contenido ideológico, relación social y forma textual).

Bajtín: polifonía, géneros discursivos socio históricos.

Figura 1: Mapa de las raíces del concepto.

Dicho concepto fue aplicado al campo de la literacidad en los ańos sesenta por el famoso pedagogo brasileño Paulo Freire, que formuló con claridad la idea de que los analfabetos son víctimas y no responsables de su condición, que la escuela es una institución creada por determinados grupos sociales para reproducir el status quo (la pedagogía de la opresión) y que el acceso a la literacidad puede ser una herramienta importante de liberación o empoderamiento de los individuos. Al aprender a leer, los sujetos obtienen poder (se "empoderan") y pueden transformar la realidad injusta que les rodea. Otros pedagogos han desarrollado estas ideas dentro del campo de la pedagogía crítica, con conceptos como currículum oculto o pensamiento crítico.

Diferentes movimientos políticos como el feminismo, la lucha contra el racismo, la ecología, el nacionalismo y el postcolonialismo, con sus correspondientes estudios culturales han contribuido a desarrollar la criticidad, al explorar la mirada con que los diferentes grupos humanos construimos la realidad y elaboramos conceptos y representaciones sociales compartidas. Estos estudios (MATTERLART; NEVEU, 2004; SARDAR; VAN LOON, 2005) han mostrado que muchos puntos de vista unánimemente aceptados son elaboraciones culturales históricamente 
situadas y construidas, que carecen de fundamento biológico. En consecuencia, pueden - deberían poder - ser transformados por la voluntad humana.

Este es también el punto de vista de algunos filósofos, cuyas aportaciones son también relevantes para el campo. Varios autores atribuyen a Jacques Derrida una formulación y actualización contemporánea del concepto de criticidad. Y muchos también reconocen el papel fundamental de las investigaciones históricas de Michel Foucault para mostrar cómo conceptos aparentemente estables o "naturales" (la locura, la normalidad, el sexo, etc.) han ido cambiando a lo largo de la historia, a partir de los discursos de las instituciones que conforman una comunidad. Según Foucault, el discurso construye la identidad, los conceptos y la cultura de una comunidad $y$ es un instrumento fundamental para ejercer el poder.

Las ciencias del lenguaje también aportan teorías y conceptos relevantes para la criticidad. La teoría sistémico-funcional de M.A.K. Halliday establece un paralelismo entre la estructura del uso lingüístico (el registro, las funciones del lenguaje) y la organización social. El Análisis Crítico del Discurso va más allá al proponer usar la teoría lingüística para analizar los discursos de los grupos dominantes y contribuir así a desenmascarar las iniquidades de determinadas situaciones. En el campo de la teoría literaria destacan los conceptos bajtinianos de género discursivo y esfera social o de polifonía.

Finalmente, los denominados nuevos estudios de literacidad aportan una mirada etnográfica sobre el hecho escrito y constituyen quizá la perspectiva más general y aglutinadora para estudiar el fenómeno de la literacidad. Barton e Hamilton (2000, p. 8) formulan estos seis principios fundamentales para explicar su concepción del uso social de la escritura:

- Entendemos mejor la literacidad si la concebimos como un conjunto de prácticas sociales, que podemos inferir a partir de los hechos de escritura, que a su vez están mediados por textos escritos.

- Hay diferentes formas de literacidad asociadas a diferentes ámbitos de la vida.

- Las prácticas de literacidad están gestionadas u organizadas (patterned) por instituciones sociales y relaciones de poder, de manera que algunas son más dominantes, visibles e influyentes que otras. 
- Las prácticas de literacidad cumplen propósitos específicos y forman parte de objetivos sociales y prácticas culturales más amplias.

- La literacidad está situada históricamente.

- Las prácticas de literacidad cambian y las nuevas formas se adquieren a menudo a partir de procesos de aprendizaje informal y de atribución de significado.

Así, en el aeropuerto, el texto escrito interactivo que muestra la pantalla táctil de una máquina de autofacturación es la punta del iceberg de una actividad más compleja y escondida. La máquina está facilitando una transacción completa entre un pasajero y un sistema de control de acceso, guiado a distancia por el personal de una determinada compañía aérea. El hecho de escritura, en cambio, incluye muchos más elementos que las pantallas táctiles:

- El lector-pasajero dispone de un billete electrónico que adquirió previamente; de modo que cada hecho escrito está conectado con otros, con los que se conforma un conjunto complejo de actos de literacidad;

- El sistema de pantallas tiene una lógica que responde a los parámetros del proceso: identificar el vuelo y el pasajero, elegir asiento, reconocer los puntos de fidelización, etc.

- El lector dispone de mucho conocimiento previo sobre la actividad que se está desarrollando: cómo hay que comportarse en un aeropuerto, cómo se accede a un avión (muy diferente a un autobús o un tren), por qué es útil facturar con una máquina, etc.

Este conjunto de hechos de escritura y de conocimientos, normas y organizaciones sociales es lo que denominamos práctica social de literacidad. La escritura se mezcla con otros elementos no verbales (aparatos, procesos administrativos, aviones, etc.) para desarrollar unos propósitos específicos, que no son estéticos, lingüísticos o literarios, sino administrativos, comerciales y profesionales. Dicha práctica se desarrolla íntegramente en instituciones particulares (aeropuerto, compañía aérea), que tienen unas prioridades (buscar beneficios, ofrecer un servicio, etc.) y que evolucionan con el paso del tiempo: cada día hay más autofacturación para ganar eficacia y reducir costes. Finalmente, los lectores aprendemos a autofacturar sin 
necesidad de ir a la escuela, con la práctica, el error y la corrección y algún ayudante, quizás espontáneo, que pueda indicarnos cómo proceder en el momento oportuno.

En el ámbito académico, un examen no es solo un escrito que muestra los conocimientos de un estudiante en una asignatura y que tiene una forma discursiva preestablecida (secuencia expositivo-argumentativa, registro formal, especificidad, etc.). También es un hecho de escritura en el que un estudiante en un aula a final de curso responde a unas preguntas que ha formulado el docente de la asignatura correspondiente (con unos roles determinados de autor y lector, formas de cortesía, contexto académico, conocimientos compartidos, etc.), en unas determinadas condiciones (limitación temporal, presión social, etc.).

Además, el examen es también una práctica social establecida históricamente en un ámbito (educación) y en una institución (escuela, instituto, universidad, etc.), que refleja unas relaciones de poder (docentediscente) y unas concepciones determinadas sobre el aprendizaje y la enseñanza. También sabemos que el género examen varía según las disciplinas y que evoluciona a lo largo de la historia. De manera que hacer un buen examen no depende solo del hecho de disponer o no de los conocimientos y de las destrezas gramaticales y léxicas correspondientes; también hay que gestionar todos los aspectos socioculturales.

\section{Diversidad de perspectivas}

Podemos distinguir tres grandes orientaciones en la concepción de lo crítico en la literacidad, desde una ausencia inicial a su completa asunción en épocas más recientes. Combinamos para ello los puntos de vista de Luke (2000); Cervetti; Pardales; Damico (2001); Serafini (2003). Cabe considerar que adaptamos estos autores norteamericanos y australianos a la sensibilidad y los puntos de vista latinos. Añadimos al conjunto una distinción entre dos perspectivas críticas, una sociocultural, de carácter más analítico, y otra sociopolítica, más implicada en la transformación social - sin que exista, a pesar de ello, una separación estricta entre los dos enfoques:

1) Perspectiva tradicional o filológica: se basa en el dominio del código y mantiene que el significado está en el texto y se desentraña con erudición. Hay una interpretación del texto que es la canónica y sólo los lectores 
expertos pueden llegar a ella. Los factores sociales e históricos están en función de la interpretación de la intención original del autor en su época; las interpretaciones alternativas deben demostrarse; de lo contrario, se consideran erróneas. Lo crítico aquí se confunde con los niveles superiores de comprensión: conseguir la interpretación canónica e identificar el propósito original del autor.

2) Perspectiva interpretativa o psicológica: se basa en los procesos cognitivos de comprensión. El significado se construye en la transacción entre un lector y un texto. El lector aporta su conocimiento previo y las inferencias necesarias para interpretarlo. La construcción del significado es un proceso interno, mental, cognitivo, de conexión y de reelaboración de la información. La comprensión es, en definitiva, una actividad individual y en términos absolutos intransferible; esto justifica las diversas interpretaciones que puede tener un mismo texto. Leer críticamente es articular una respuesta personal al mismo.

3) Perspectiva crítica: se basa en la conformación social del sentido del texto. El significado se construye en contextos sociales, políticos y culturales, que provocan en los receptores unas interpretaciones determinadas históricamente y localmente. El lector debe saber interpretar estos contextos y situarse respecto a ellos para entender el texto de manera completa. Comprender implica, en una perspectiva social, posicionarse. En este tercer enfoque podemos distinguir dos orientaciones:

- sociocultural: el énfasis se pone en ser crítico para comprender mejor el mundo, su complejidad, su diversidad intrínseca y el juego de intereses que lo conforman, atendiendo con especial cuidado a los discursos públicos que organizan y determinan ideológicamente nuestras sociedades tecnológicas y cada vez más globalizadas. Leer críticamente significa aceptar la relatividad de cualquier interpretación, incluso la propia.

- sociopolítica: prioriza la acción social que supone el texto y la reacción del lector. El significado de un texto, así como los individuos que lo elaboran o lo leen, están situados siempre dentro de sistemas sociopolíticos. Cualquier producción discursiva tiene la función de perpetuar el sistema o bien de resistirse a él (si un texto es aparentemente neutro, en realidad contribuye a la perpetuación). 
Ser crítico supone cuestionar el sistema y actuar para transformarlo. El énfasis se pone en ser crítico para cambiar el mundo y luchar contra la injusticia y las desigualdades.

Desde nuestra mirada latina, una práctica didáctica abiertamente sociopolítica (b) genera fácilmente recelos u oposición, especialmente si se desconecta de la más analítica o sociocultural (a). Una lectura crítica centrada en lo político (b) que prescinda de (a) aparece como dogmática o ciega, carente de racionalidad. Por otro lado, resulta difícil - e innecesario - empeñarse en mantener una frontera impermeable entre los dos enfoques. En teoría puede existir un análisis que se limite a comprender el mundo (a), pero si el análisis es profundo lo más normal es que desemboque en alguna forma de actuación transformadora (b). La práctica habitual de descubrir lo que se esconde tras las líneas lleva fácilmente al alumnado a un deseo de justicia e igualdad, sin necesidad de presionarlo. A nuestro parecer, no se trata de empezar adoctrinando sino de acabar conociendo muy bien las intenciones de las doctrinas a las que estamos expuestos.

Ser crítico implica, como hemos dicho, no ser dogmático sino relativista. Pero también existen limitaciones a la idea de que "todas las interpretaciones son posibles e igualmente válidas". Sin duda todas son respetables si son respetuosas. También son todas ciertas - en el supuesto de que efectivamente hayan existido en un contexto particular real y determinado y de que fueran honestas. Pero no todas consiguen el mismo grado de significación, coherencia o plausibilidad. Hay interpretaciones delirantes y desconectadas del texto y del contexto, que necesitan ser mejoradas, y las hay también torticeras y malintencionadas, que deben ser puestas al descubierto.

El relativismo ha sido discutido ampliamente en filosofía y en política, tanto desde las idelogías de lo absoluto - especialmente, las religiones o las visiones esencialistas del arte -, como desde posiciones críticas. Varios autores (GIDDENS, 1993; FLECHA, 1994; VALDECANTOS, 1999) señalan sus contradicciones y lo conciben como un error en la evolución cultural de Occidente, una consecuencia perniciosa de la posmodernidad que disgrega las ideologías, achica las utopías y acaba con las esperanzas de progreso y de transformación del mundo hacia la igualdad y la justicia. El relativismo, de raíz nietzschena e inspirador de los ya mencionados Derrida y Foucault al situar el lenguaje en el centro y considerar que cualquier 
verdad está situada sociohistóricamente, pone en tela de juicio tanto las ideas tradicionales del antiguo régimen com los principios de igualdad, libertad y fraternidad que caracterizan a la modernidad. Para los críticos del relativismo, éste constituye una proclamación del fin de la razón y la certeza que solo conduce al escepticismo y al nihilismo.

Sin embargo, otros autores de carácter crítico (MARSHALL, 1990; SIEGEL; FERNÁNDEZ, 2000; LUKE, 2000) consideran que la orientación genealógica de Foucault y el deconstruccionismo de Derrida son fundamentos importantes para la crítica social. El propio Giroux (1988, 1994), abierto partidario de una perspectiva crítica sociopolítica y opositora - y reivindicador de la figura de Gramsci -, plantea que es preciso orientar la educación a partir de la realidad posmoderna de la juventud actual, sin "esencializar los referentes éticos", pero al mismo tiempo afrontando "la ética como algo diferente de una víctima de un inconmensurable juego de palabras". ${ }^{2}$

Desde nuestro punto de vista, después de Saussure, Wittgenstein y Austin, teorizan, respectivamente, sobre la naturaleza representativa, contingente y agentiva del lenguaje, y de los estudios antropológicos y etnográficos sobre el discurso (Malinowsky, Gumperz y Hymes, etc.), resulta imposible prescindir de la relatividad en la interpretación de los textos dentro del complejo entramado de la comunicación humana. Como afirma Santiesteban (2004, p. 379)

el relativismo no es un obstáculo para el aprendizaje,
sino una realidad educativa que ha de conducir hacia
el análisis de valores y la comprensión de opiniones
divergentes; hoy en día no puede entenderse el
mundo social desde posiciones irreductibles, sino a
través del contraste de interpretaciones contrapuestas.

Es decir, lo relativo no debe conducir necesariamente al "todo vale" ni a "la nada", como argumentan sus detractores, sino a una visión plural del mundo y respetuosa con las opiniones ajenas, que no tiene por qué ser neutral ni conformista, ni renunciar a convencer al otro por la única vía del diálogo. ${ }^{3}$

Lo necesario es construir a partir del desmoronamiento de las grandes narrativas de la modernidad la posibilidad de comprender el mundo y los 
discursos que lo rodean y lo constituyen. Y esa comprensión sólo puede darse si se acepta que:

- no hay una única interpretación de los discursos,

- que cada uno - el autor y los diferentes lectores - interpreta de un modo diferente, y

- que cualquier interpretación individual està situada sociohistóricamente y es, por lo tanto, parcial, o lo que es lo mismo, relativa.

El lector o el oyente crítico busca una visión global de "lo que yo entiendo" + "lo que creo que el autor quiere decir y quiere conseguir de mi" + "lo que otros lectores van a entender y cómo van a reaccionar", para lograr una representación más ajustada de los efectos que un texto pueda causar en una comunidad, para poder posicionarse respecto a él $-\mathrm{y}$ para poder actuar políticamente si así lo considera.

Se trata, en resumen, de recuperar el significado etimológico de la palabra crítico - del griego kritikós, adjetivo derivado de krisis 'juicio, decisión' - según el cual una persona crítica es capaz de juzgar y decidir ante un problema - una "crisis" - con criterio y discernimiento. Y para hacerlo bien debe poder elegir entre más de una opción interpretativa, sin estar solo imbuida o atrapada en la ideología hegemónica y, como se expresa en la propuesta de Freire el conocimiento como algo problemático y objeto de indagación.

\section{Literacidad crítica y acrítica}

La capacidad crítica tiene consecuencias importantes en la manera en que las personas se enfrentan a los textos. Hay varias actitudes y aptitudes que se están asociadas a la lectura crítica y que suelen ser ausentes de la que no lo es. A continuación presentamos un contraste polarizado entre estos dos tipos de lectura. ${ }^{4}$ Debe tenerse en cuenta que esta aproximación dicotómica admite muchas combinaciones intermedias según el lector, el texto que se lee, el interés por el tema, la función del acto de lectura e, incluso, factores poco controlables como la hora del día, el cansancio, etc. Por otra parte, solo se contrastan formas de lectura, mientras que la literacidad incluye también la producción escrita y la oralidad formal. 


\section{Lector acrítico}

Efectúa una lectura plana y literal.

Tiene poco en cuenta el contexto.

Hace una interpretación absoluta: tiende a creerlo todo o nada (o a no importarle).

Tiende a pensar que las cosas son sólo de una manera.

Suele aceptar las informaciones cómo se las explican.

Simplifica los mensajes que lee (y los prefiere simples).

Tiene y quiere poca información.

No se implica en la recepción del mensaje y tiende a la pasividad.

Se interesa por pocos temas.

No le interesan el lenguaje ni la precisión.

No analiza el texto, su estructura o su argumentación.

Hay una actitud pasiva después de la lectura y la comprensión.

En la lectura de estudio, tiende sólo a memorizar y lo hace sin placer.

\section{Lector crítico}

Efectúa una lectura poliédrica y compleja.

Utiliza el contexto (o se da cuenta de que le falta algo y, si es preciso, lo busca o lo pregunta).

Hace una interpretación relativa: distingue, selecciona (y puede cuestionar parcialmente el texto).

Tiende a pensar que las cosas cambian según el punto de vista.

Suele cuestionar la veracidad de la información, su coherencia interna, preguntarse con qué interés se la dan, a quien beneficia, qué clase de persona la ha escrito, etc.

Ama la precisión y considera los matices. Piensa que el resumen puede obviar u ocultar aspectos importantes de un tema.

Pide mucha información y sabe manejarla.

Se implica en el mensaje y se posiciona respecto a su contenido.

Se interesa por el mundo que le rodea.

Se fija en las palabras y los significados, y le gusta jugar con ellos.

Analiza y juzga los textos según su coherencia, su calidad argumentativa, etc.

Después de leer y comprender, el lector reacciona, habla, actúa, interviene. Adopta una actitud activa e interactiva. En la lectura de estudio, tiende a relacionar y a argumentar (e incluso memoriza con placer). 
En conjunto, la lectura crítica se sabe elaborada, compleja, humilde, cargada de matices y razonamientos, dúctil, insatisfecha, exploradora, capaz de discutir e, incluso, de cambiar de opinión de forma razonada; es la lectura que aspira a comprender la complejidad de lo humano, psicológico y social, y a transformalo si es preciso. Al contrario, la acrítica se nos representa como sencilla, rápida, directa, simplificadora, autosatisfecha, esquemática y muchos otros adjetivos - no hay duda de que muchas de las características que aquí atribuimos a uno y otro tipo de lector tienen implicaciones didácticas de gran envergadura, que intentaremos desarrollar con detalle en otra ocasión.

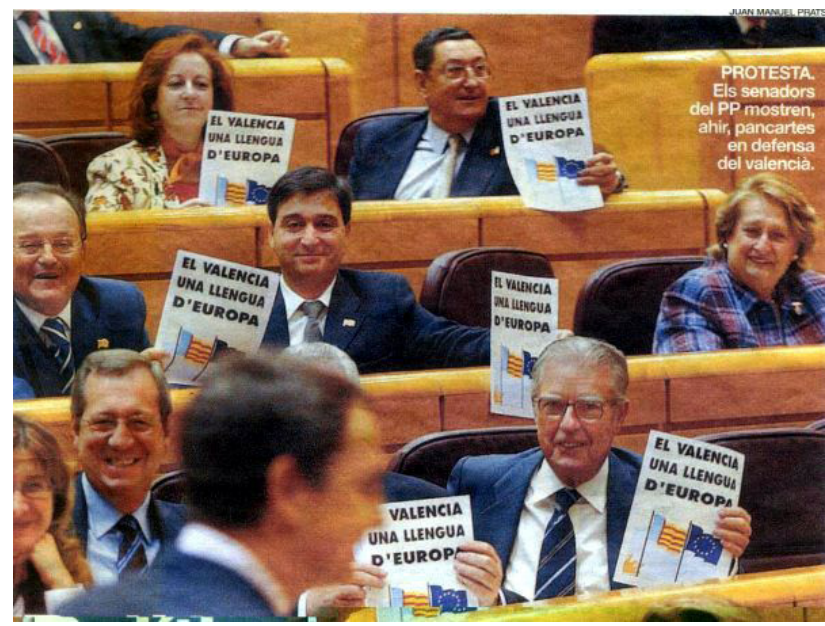

Figura 2: El valenciano una llengua d'Europa.

Fonte: El Periódico 18-11-04.

\section{Ejemplo}

Las Cortes Valencianas mostraron este aspecto en la visita del presidente del gobierno español (El valenciano lengua de Europa, en castellano). El pie de página del rotativo escribe también: PROTESTA. Los senadores del PP muestran, ayer, pancartas en defensa del valenciano.

¿Qué significa leer críticamente esta pancarta y la foto-noticia correspondiente? El lector que aplique la lógica razonará que estos 
parlamentarios (del PP o Partido Popular, agrupación conservadora) defienden su lengua ante alguien (¿la persona que aparece en primer plano?) que lógicamente debe pertenecer a otro partido y que la ataca o que no acepta que adquiera estatus reconocido. (Nadie argumenta a favor de nada o a favor de lo obvio; cualquier tesis tiene su antítesis.) Si además el lector sabe o reconoce que este primer plano corresponde al presidente del gobierno español de aquella fecha (José Luis Rodríguez Zapatero), que pertenece al Partido Socialista Obrero Espańol (o PSOE, de izquierdas), la interpretación adquiere cierta coherencia aparente. Pero esta interpretación - aunque respetable - carece de plausibilidad si consideramos datos y circunstancias relevantes.

Conocer la realidad sociolingüística valenciana permite dar otros sentidos a este hecho escrito. Algunos grupos políticos y culturales valencianos rechazan la evidencia histórica y científica de que el habla valenciana y la catalana tienen escasas variaciones y pertenecen al mismo idioma (según la comunidad científica: Academia Valenciana de la Lengua, Institut d'Estudis Catalans, universidades). En el pasado el gobierno del PP en Valencia ha apoyado a estos grupos, hasta el punto de fomentar actitudes secesionistas: imponer una ortografía particular para su variedad lingüística, impedir que los maestros catalanes ejerzan en Valencia, etc. Muchos especialistas consideran que detrás de estas decisiones no hay tanto interés por revitalizar la lengua propia como un propósito oculto de dividir el catalán/valenciano, impedir su desarrollo y facilitar su sustitución lingüística completa por el castellano.

Cuando antes de la noticia comentada el gobierno español tramitó la posibilidad de usar el catalán/valenciano en Europa, el PP rechazó esta opción argumentando que se negaba la categoría de lengua europea a la variedad valenciana. Para muchos lingüistas, esta actitud sigue la mencionada lógica oculta, puesto que en el marco europeo parece tener más posibilidades de éxito una única lengua más hablada (11 millones de catalanes y valencianos), con algunas variaciones dialectales, que dos variedades con estatus diferente pero muy cercanas, más minoritarias ( 7 millones de hablantes catalanes y 4 de valencianos).

Así, el propósito último del cartel El valencia una llengua d'Europa no es tanto defender un idioma como erosionar al gobierno y a su presidente. Corrobora esta conclusión otros actos escritos parecidos, acaecidos en otros 
parlamentos con protagonistas del mismo signo político, que coinciden en el propósito de criticar ferozmente al gobierno con formas populistas y demagógicas, utilizando otros temas: educación, ley del matrimonio gay, etc. (Por supuesto, esta no es una interpretación neutra, que posea la Verdad en mayúscula. Nuestro punto de vista también está situado y se expone de manera clara y honesta. Otras personas defenderán otras interpretaciones respetables desde otros horizontes, aunque no siempre se quieran mostrar con transparencia.)

Este breve ejemplo de análisis de un texto público muestra la complejidad que implica la comprensión crítica. Interpretar requiere acceder a mucho conocimiento sociocultural de la comunidad en la que se sucede el hecho escrito. Requiere conocer detalles importantes de la historia, de la correlación de fuerzas políticas, de las instituciones en cuyo seno se desarrolla el acto de literacidad, etc.

\section{Resumen: nuestro punto de vista}

Desde nuestra perspectiva, cualquier texto tiene contenido e ideología y saber procesarlos y comprenderlo requiere recuperar ambas cosas. Por ideología entendemos no solo el propósito o la opción política del autor del texto, sino el conjunto de representaciones sociales que configuran una cultura (el conocimiento, los valores y las actitudes que comparten los miembros de una comunidad) y que se insertan inevitablemente en cualquier discurso producido en la misma y para la misma.

Desde esta perspectiva, comprender críticamente requiere:

1) Situar el discurso en el contexto sociocultural de partida. Entre otros aspectos, este punto incluye la capacidad de identificar el propósito y situarlo en el entramado de intereses de la comunidad; reconocer el contenido incluido en el texto (y el que se ha evitado); identificar las voces incorporadas (autores, citas, ecos, etc.) y las calladas; detectar posicionamientos ideológicos (sexo, raza, cultura, etc.); caracterizar la voz del autor (idiolecto, registro, uso linguístico, etc.), o identificar los significados particulares que construye el autor.

2) Reconocer y participar en la práctica discursiva. A modo de ejemplo, este punto implica saber interpretar el escrito según su género discursivo (columna de opinión, artículo científico, correo electrónico, etc.); 
reconocer las características socioculturales propias del género (estructura, estilo, saludo, etc.), o identificar el uso que hace el autor de la tradición del género.

\section{3) Calcular los efectos que causa un discurso en la comunidad y en} uno mismo. Entre otras cuestiones, requiere tomar conciencia de la propia situacionalidad y de lo que los textos pretenden que se crea o se haga; calcular las interpretaciones de los otros, o integrar estas interpretaciones en un todo.

\section{Notas}

1 Este artículo forma parte de los trabajos de investigación del grupo Literacidad critica, cuyo propósito principal es investigar desde una perspectiva sociocultural las nuevas formas de lectura y escritura, incluida su enseñanza, poniendo énfasis en la necesidad de incorporar una perspectiva crítica. La labor del grupo se ha desarrollado hasta el momento a través de dos proyectos: el primero se tituló La competencia receptiva crítica: análisis y propuesta didáctica (CASSANY, 2004-2007), y el segundo Descripción de algunas prácticas letradas recientes. Anàlisis lingüistico y propuesta didàctica, (CASSANY, 2007-2010). El grupo, coordinador por Daniel Cassany y con sede en la Universitat Pompeu Fabra, también forma parte de Gr@el (Grup de Recerca sobre Aprenentatge i Ensenyament de Llengües), que posee la categoría de grupo de investigación consolidado por la Agència de Gestió d'Ajuts Universitaris i de Recerca (Agaur; resolución del 3-7-2009; núm. expedient: 2009 SGR 803). En la web del grupo se exponen con más detalle los objetivos, la metodología y los fundamentos de estos proyectos, así como todos sus trabajos e informes ya publicados. (UNIVERSIDAD POMPEU FABRA, 2009).

2 Incluso los filósofos de la Escuela de Frankfurt, fervientes promotores del ideal ilustrado "propagar la razón para iluminar el mundo", después de la tremenda decepción ante la condición humana causada por el nazismo, acaban incorporando a su contructo teórico el misterio de la mística y la capacidad comunicativa del arte - incluyendo el encargo inconcluso de Horkheimer a Benjamin de tratar de relacionar el psicoanálisis con su línea de trabajo marxista. De algún modo, llegan por distinto camino a una conclusión parecida a la que Steiner (1967) atribuye a la célebre última 
proposición del Tractatus logico-philosophicus de Wittgenstein: "De aquello de lo que no se puede hablar, hay que guardar silencio", es decir, dejar que fluya fuera de la esfera de lo racional, en el sentimiento o en el silencio.

3 El principio "todo es relativo" implica su propia relatividad, por lo que algo habrá que no sea relativo, o por lo menos, que no sea absolutamente relativo sino relativamente relativo. Por nuestra parte, nos inclinaríamos a buscar lo común en lo humano más en la Declaración Universal de los Derechos Humanos y menos en la moral absoluta de las religiones o los totalitarismos de cualquier signo.

4 La elaboración de este apartado del artículo tuvo la colaboración inestimable de Cristina Aliagas.

\section{REFERÊNCIAS}

AMES, Patricia. Para ser iguales, para ser distintos: educación, escritura y poder en el Perú. Lima: Instituto de Estudios Peruanos, 2002.

BARTON, David; HAMILTON, Mary. Literacy practices. In: ; IVANIC, Roz. Situated Literacies: reading and writing in context. Londres: Routledge, 2000. p. 7-15.

CASSANY, Daniel (Coord.). La competencia receptiva critica: análisis y propuesta didáctica. Barcelona: Centro de inscripción/Departamento de Traducción y Filología / Universidad Pompeu Fabra , 2004-2007. Projeto financiado por el Ministerio de Educación y Ciencia, del 12-12-2004 al 12-12-2007. Referencia: HUM 2004-03772/FILO. Disponível em: $<$ http://www.upf.edu/dtf/recerca/grups/grael/LC/index.html>. Acesso em: 1 dez. 2010.

CASSANY, Daniel (Coord.). Descripción de algunas prácticas letradas recientes: anàlisis lingüístico y propuesta didàctica. Barcelona: Centro de inscripción/Departamento de Traducción y Filología /Universidad Pompeu Fabra, 2007-2010. (HUM2007-62118/FILO).

CASSANY, Daniel. Los significados de la comprensión crítica. Lectura y Vida, Revista Latinomericana de Lectura, Newark, De,USA, v. 26, n. 3, p. 32-45, 2005. 
CERVETTI, Gina; PARDALES, Michael J.; DAMICO James S. A tale of differences: comparing the traditions, perspectives, and educational goals of critical reading and critical literacy. Reading Online, Newark, De,USA, v. 4, n. 9, 2001. Disponível em: <www.readingonline.org/ articles/art_index.asp?HREF=/articles/cervetti/index.html $>$. Acesso em: 1 dez. 2010.

FLECHA, Ramón. Las nuevas desigualdades educativas. In: CASTELLS, Manuel. Nuevas perspectivas criticas en educación. Barcelona: Paidós, 1994. p. 57-82.

GIDDENS, Anthony. Consecuencias de la modernidad. Madrid: Alianza, 1993.

GIROUX, Henry. Los profesors como intelectuales: hacia una pedagogía crítica del aprendizaje. Barcelona: Paidós/MEC, 1988.

GIROUX, Henry. Jóvenes, diferencia y educación postmoderna. In: CASTELLS, Manuel et al. Nuevas perspectivas criticas en educación. Barcelona: Paidós, 1994. p. 99-128.

LEAL CARRETERO, Fernando. ¿Qué es crítico? Apuntes para la historia de un término. Revista Mexicana de Investigación Educativa, Mexico, DF, v. 8. n. 17, p. 245-261, 2003. Disponível em: <http://www. comie.org. $\mathrm{mx} / \mathrm{v} 1 /$ revista/portal.php?idm=es\&sec=SC03\&\&sub=SBB\&cr iterio=ART00372 >. Acesso em: 1 dez. 2010.

LUKE, Allan. Critical Literacy in Australia. Journal of Adolescent and Adult Literacy, Newark, De,USA, v. 43, n. 5, p. 448-461, feb. 2000. Disponível em:<www.btr.qld.edu.au/papers/critlit.html>. Acesso em: 1 dez. 2010.

MARÍ, Isidor. Nuevas tecnologías y aprendizaje de la lectura en un mundo multilingüe. In: ENCUENTRO INTERNACIONAL SOBRE LECTURA Y DESARROLLO: FERIA INTERNACIONAL DEL LIBRO DE GUADALAJARA, 4., 2005, Guadalajara. Anais... Guadalajara: [s.n.], 2005.

MARSHALL, James D. Foucault and Eduacational Research. In: BALL, S. J. Foucault and Education: disciplines and Knowledge. Londres: Nueva York: Routledge, 1990. p. 11-28. 
MATTERLART, Armand; NEVEU, Érik. Introducción a los estudios culturales. Barcelona: Paidós, 2004.

SERAFINI, Frank. Informing our practice: modernist, transactional, and critical perspectives on children's literature and reading instruction. Reading Online, Newark, De, USA, v. 6, n. 6, feb. 2003. Disponível em: $<$ www.readingonline.org/articles/art_index.asp?HREF=serafini/index. html>. Acesso em: 1 dez. 2010.

SANTIESTEBAN, Antoni. Formación de la ciudadanía y educación política. In: MUÑOZ, Maria Isabel Vera; PÉREZ, David Pérez i

(Coord.). Formación de la ciudadanía: las TICs y los nuevos problemas. Espanha: AUPDCS, 2004. p. 377-388.

SARDAR, Ziauddin; VAN LOON, Borin. Estudios culturales para todos. Barcelona: Paidós, 2005.

SIEGEL, Marjorie; FERNÁNDEZ, Susana Laura. Critical approaches. In: KAMIL, Michael. et al. Handbook of reading research. Mahwah, NJ: Erlbaum, 2000. v. 3, p. 141-151.

STEINER, George. Lenguaje y silencio: ensayos sobre la literatura, el lenguaje y lo inhumano. Barcelona: Gedisa, 1967.

UNIVERSIDAD POMPEU FABRA. Departament de Traducción i Ciències del llenguatge. Agència de Gestió d'Ajuts Universitaris i de Recerca (Agaur). Barcelona, 2009. Disponível em:< http://www.upf. edu/dtf/ recerca/grups/grael/LC/>. Acesso em: 1 dez. 2010.

VALDECANTOS, Antonio. Contra el relativismo. Madrid: Visor, 1999.

VICH, Víctor; ZAVALA, Virginia. Oralidad y poder: herramientas metodológicas. Buenos Aires: Norma, 2004.

ZAVALA, Virginia. Desencuentros con la escritura: escuela y comunidad en los andes peruanos. Lima: Red para el desarrollo de las ciencias sociales en el Perú, 2002. 


\section{Aproximação ao letramento crítico}

\section{Resumo}

Exploramos aqui os conceitos de letramento e de critica, ou de leitura e escrita de ideologias, tomando "ideologia" como o posicionamento que um autor toma em seu texto sobre qualquer questão (política, social, desportiva, etc.). Analisamos o campo semântico de ambos os conceitos, suas raízes filosóficas, pedagógicas e linguísticas, e os vocábulos usados em vários idiomas para denominá-los. Formulamos finalmente a distinção teórica entre um leitor crítico e a-crítico, a partir das abordagens da Análise Crítica do Discurso, e os exemplificamos com o caso de um planfleto político com 5 palavras.

Palavras-chave: Alfabetização. Leitura.

\section{Approaching Critical Literacy}

\section{Abstract}

We explore the concepts of literacy and critique, or the reading and writing of ideologies, understanding "ideology" as the author's point of view in his text on any question (political, social, sports, etc.). We analyse the field of semantics of both of the concepts, their philosophical, pedagogical and linguistic roots, and the words used in several languages to refer to them. We formulate finally the theoretical distinction between a critical reader and an uncritical one, based on the contributions of the Critical Discourse Analysis, and we exemplify it with the case of a political five-word board.

Keywords: Literacy. Reading.

\section{Daniel Cassany}

C. Roc Boronat, 13808018 BARCELONA (España); despacho: 53.606

Telefone: +34 935422253

E-mail: daniel.cassany@upf.edu

\section{Josep M. Castellà}

C. Ramon Trias Fargas, 25-27 08005 BARCELONA (España); despacho 20.2E50 Telefone: +34935422604

E-mail: josep.castella@upf.edu 